\title{
Wear Behavior of the Multiheterostructured AZ91 Mg Alloy Prepared by ECAP and Aging
}

\author{
Bingqian Xu, ${ }^{1}$ Jiapeng Sun $\mathbb{D}^{1},{ }^{1}$ Zhenquan Yang, ${ }^{1}$ Jing Han, ${ }^{2}$ Dan Song, ${ }^{1}$ Jinghua Jiang, \\ and Aibin Ma ${ }^{1}$ \\ ${ }^{1}$ College of Mechanics and Materials, Hohai University, Nanjing 210098, China \\ ${ }^{2}$ School of Mechanical and Electrical Engineering, China University of Mining and Technology, Xuzhou, \\ 221116 Jiangsu Province, China
}

Correspondence should be addressed to Jiapeng Sun; sunpengp@hhu.edu.cn and Aibin Ma; aibin-ma@hhu.edu.cn Received 24 May 2020; Accepted 9 June 2020; Published 9 July 2020

Guest Editor: Ying Zhao

Copyright (c) 2020 Bingqian Xu et al. This is an open access article distributed under the Creative Commons Attribution License, which permits unrestricted use, distribution, and reproduction in any medium, provided the original work is properly cited.

\begin{abstract}
The microstructure design based on the development of heterostructure provides a new way for high strength and ductility $\mathrm{Mg}$ alloys. However, the wear property, as an important service performance, of $\mathrm{Mg}$ alloys with heterostructure is scarcely investigated. In this work, a high strength and ductility AZ91 Mg alloy with multiheterostructure was prepared via a processing route combined industrial-scale equal channel angular pressing (ECAP) and aging. The multiheterostructure consists of the heterogeneous grain structure and heterogeneous precipitates. The dry sliding wear behavior of this multiheterostructured ( $\mathrm{MH}$ ) alloy is investigated compared to the as-cast alloy. The impacts of the applied load and duration time on the wear volume and coefficient of friction (COF) are analyzed, and the wear mechanism is further discussed. The result indicates that although the $\mathrm{MH}$ alloy exhibits high-desirable strength-ductility synergy, it shows a poorer wear resistance but a relatively lower COF compared to the as-cast alloy at the present condition. The wear mechanism of both alloys mainly involves abrasive wear, as well as mild adhesion, delamination, and oxidation. In comparison, the MH alloy shows relatively severe adhesion, delamination, and oxidation. The poor wear resistance of the $\mathrm{MH}$ alloy at the present dry sliding wear condition is linked to the abundant grain boundaries and fine precipitates. Therefore, one should reasonably use the $\mathrm{MH} \mathrm{Mg}$ alloy considering the service conditions to seek advantages and avoid disadvantages.
\end{abstract}

\section{Introduction}

According to the need for lightweight of the structural materials, magnesium $(\mathrm{Mg})$ alloys, as the lightest structural metallic materials, are widely applied in the automobile, aerospace, biomedicine application, and electronics industries [1-5]. Moreover, profiting from all kinds of processing methods, numerous high strength $\mathrm{Mg}$ alloys have been produced in the laboratory and even some $\mathrm{Mg}$ alloys have been commercialized, such as Mg-Al-Zn (AZ)-typed alloys and Mg-Zn-Zr (ZK)-typed alloys [6-9]. However, the absolute strength and ductility of $\mathrm{Mg}$ alloys at room temperature are still much lower than that of Al alloys, Ti alloys, and steels, which restrict their widespread commercial applications. Therefore, great effort has been made to enhance the mechanical properties of the $\mathrm{Mg}$ alloys in the last few decades [10-13].

Due to the well-known Hall-Petch law, the ultrafine/nanograined $\mathrm{Mg}$ alloys are intensely pursued to address the issues of poor strength and ductility [14-19]. In recent years, the microstructure design based on the development of the heterostructure provides a new way for the high-performance materials [20-23]. Many studies indicate that the heterostructure brings into much higher strength and ductility in several $\mathrm{Mg}$ alloys than the generally developed ultrafine grain structure [24, 25]. For example, Ramezani et al. [26] developed a GWZ Mg-8.1Gd-4.3Y-1.6Zn-0.4Zr (wt. \%) alloy with finegrained bimodal microstructures via multiaxial forging. The forged alloy exhibited an excellent ultimate tensile strength 
(UTS) and ductility of $581 \mathrm{MPa}$ and $15.9 \%$, respectively. Jiang et al. [27] processed a heterogeneous $\mathrm{Mg}-1 \mathrm{Gd} / \mathrm{Mg}-13 \mathrm{Gd}$ alloy laminate via accumulative extrusion bonding (AEB), whose strength and ductility were much superior to that of the individual component material. Wu et al. [28] demonstrated that the bimodal structure brought into high strength in the Mg-15Gd-1Zn-0.4Zr (wt. \%) alloys. Xu et al. [29] prepared a bimodal-structured Mg-8.2Gd-3.8Y-1Zn-0.4Zr (wt. \%) alloy using hot extrusion and aging, which had a superior strength-ductility balance. In our previous work, the laboratory scale and industrial-scale multiheterostructured AZ91 alloys were prepared via the combined processing route of ECAP and aging [30-32]. The multiheterostructured AZ91 alloy exceeded the known strength and ductility limits of the AZ91 alloy.

Compared to the abundant investigation on the mechanical properties, the wear behavior of $\mathrm{Mg}$ alloys is scarcely investigated, so that we still cannot confirm whether these high-performance Mg alloys with heterostructure have excellent wear resistance. The present work aims to investigate the dry sliding wear behavior of a multiheterostructured AZ91 alloy produced by a processing route combined industrialscale ECAP with aging. The impacts of the applied load and duration time on the wear volume and coefficient of friction (COF) were investigated, and the wear mechanism was further discussed.

\section{Experimental Procedure}

A commercial as-cast AZ91 alloy ingot with a nominal chemical composition of 9 wt. \% Al, 1 wt. \% $\mathrm{Zn}$, and 0.5 wt. \% Mn was used in this work. A combined processing route of industrial-scale ECAP with aging was used to prepare the multiheterostructure AZ91 alloy. The received AZ91 alloy was referred to as "AC alloy." The AC alloy was firstly homogenized at $420^{\circ} \mathrm{C}$ for $24 \mathrm{~h}$ followed by water quenching. Next, a homemade upscaled rotary die equal channel angular pressing (RD-ECAP) with four equal square channels $(50 \mathrm{~mm} \times 50 \mathrm{~mm} \times 100 \mathrm{~mm})$ was continually performed for 16 passes with a ram speed of $3.5 \mathrm{~mm} / \mathrm{s}$ at a constant temperature of $350^{\circ} \mathrm{C}$, followed by rapidly water cooling. Finally, the ECAPed samples were isothermally aged at $200^{\circ} \mathrm{C}$ for $15 \mathrm{~h}$, where the peak hardness was obtained. More details on the processing route can be found in our previous work [30], and the resultant sample was designated as "MH alloy."

The wear test was performed by a ball-on-disc facility (MFT-3001 type-Lanzhou Huahui Instrument Technology Co., LTD., China), as illustrated in Figure 1. Before wear testing, the samples were ground to 800 grit $\mathrm{SiC}$ sandpapers and cleaned with ethanol. The roughness of the samples is $R a$ $0.31 \mu \mathrm{m}$. The $\mathrm{Si}_{3} \mathrm{~N}_{4}$ ball with a diameter of $6 \mathrm{~mm}$ was used. All the tests were performed at a velocity of $300 \mathrm{r} / \mathrm{min}$ with a revolution radius of $2.5 \mathrm{~cm}$. Since duration time $(T)$ and applied load $(L)$ have a great influence on wear behavior, different duration times ( $T=10 \mathrm{~min}, 30 \mathrm{~min}$, and $90 \mathrm{~min}$ ) and applied loads $(L=4.9 \mathrm{~N}, 9.8 \mathrm{~N}$, and $14.7 \mathrm{~N})$ were chosen to reveal their effect on the wear behavior of the AC and $\mathrm{MH}$ alloys. When the duration time was varied, the constant applied load was $4.9 \mathrm{~N}$. When the applied load was varied,

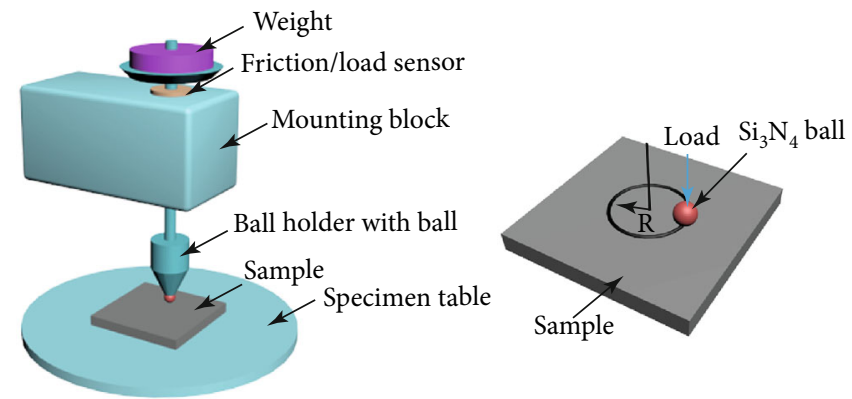

FIgURE 1: Schematic illustration of the ball-on-disc facility for the wear test.

the constant duration time was $30 \mathrm{~min}$. For each state, at least two specimens were tested. After wear testing, the samples were ultrasonically cleaned with ethanol for 5-10 min and then stored in kerosene. The wear track was characterized by the surface profile meter (TIME3222 Beijing Time High Technology LTD, China). The wear volume was calculated according to the measured cross-section profiles, which was expressed as the product of the cross-sectional area and the length of the wear track. The micro-hardness of the samples was measured by an HXD-1000TC microhardness-testing instrument with a load of $4.9 \mathrm{~N}$ and a dwelling time of $15 \mathrm{~s}$.

The microstructures were characterized by scanning electron microscopy with the secondary electron detector (SEM) equipped with an energy dispersive spectrometer (EDS) and electron backscattered diffraction (EBSD). For SEM observation, the samples were ground to 2000 grit $\mathrm{SiC}$ sandpaper successively, mechanically polished by a $1.5 \mu \mathrm{m}$ diamond suspension, and then etched by a mixture solution of acetic acid, picric acid, ethanol, and distilled water. Whereas, the EBSD samples were ground, polished, and then ion milled.

\section{Results and Discussions}

3.1. Microstructure and Mechanical Properties. Figure 2 shows the SEM micrographs of the AC alloy. This alloy is featured with a typical dendritic structure which consists of a coarse $\alpha-\mathrm{Mg}$ matrix with an average grain size of $180 \mu \mathrm{m}, \gamma$-phase precipitates $\left(\mathrm{Mg}_{17} \mathrm{Al}_{12}\right)$, and interdendritic eutectic phase.

The present used combined processing route brings into a multiheterostructured (MH) AZ91 alloy, which was investigated in detail in our previous work [30]. The microstructure of the $\mathrm{MH}$ alloy is characterized by a heterogeneous grain structure and a heterogeneous precipitate structure, as shown in Figure 3. The SEM indicates that the fine lamellar $\gamma$-phase precipitates cover most of the grains, but some grains are still precipitate-sparse/free, indicating a heterogeneous precipitate structure, as shown in Figures 3(a) and 3(b). Here, the lamellar precipitates are formed during aging in a discontinuous mode. Besides, some cobblestone-like $\gamma$ phase particles can be found on the grain boundaries, which are dynamically precipitated during ECAP processing. The EBSD observation shows that the heterogeneous grain structure is comprised of coarse grains with an average size of $44.2 \mu \mathrm{m}$ and fine grains with an average size of $18.7 \mu \mathrm{m}$, 


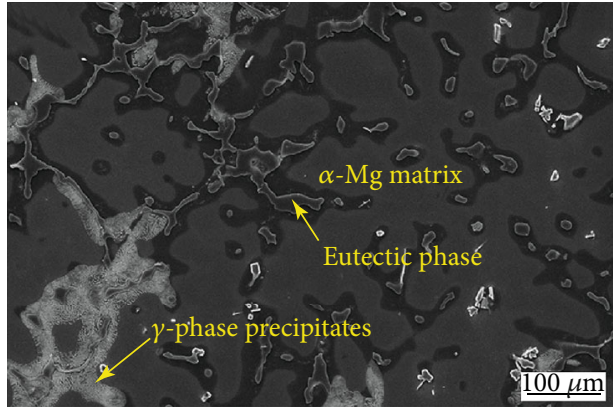

(a)

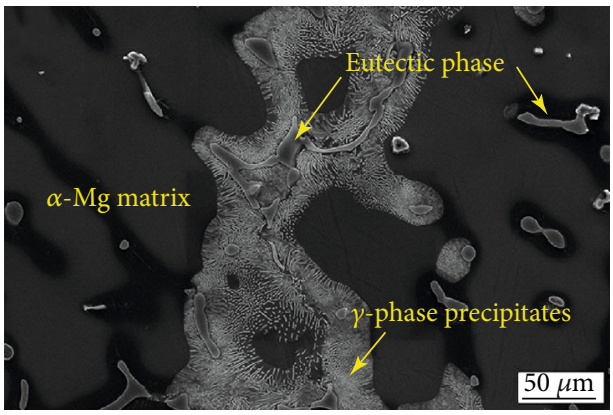

(b)

FIgURE 2: SEM micrographs of the AC alloy. The low-magnification (a) and high-magnification (b) images.

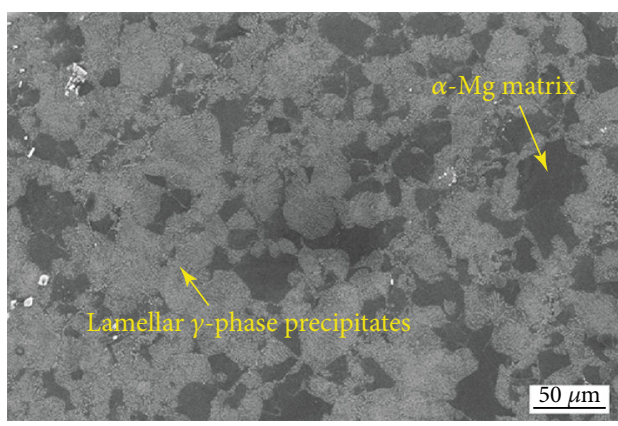

(a)

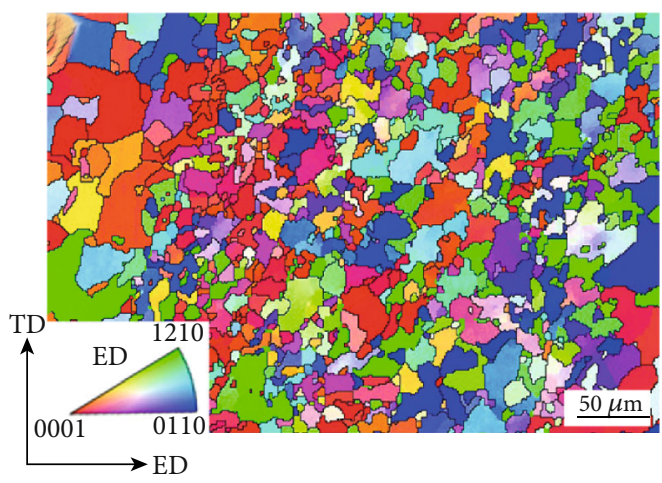

(c)

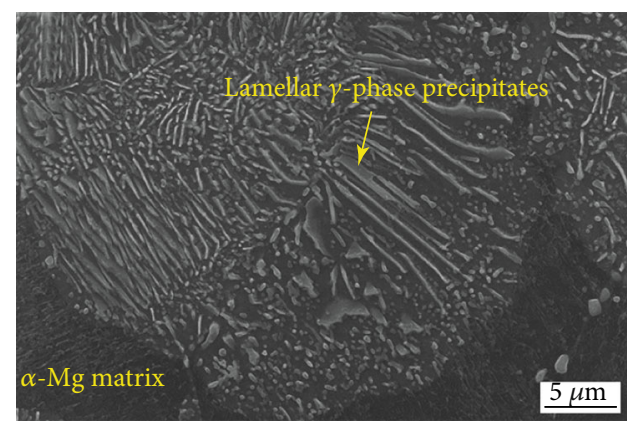

(b)

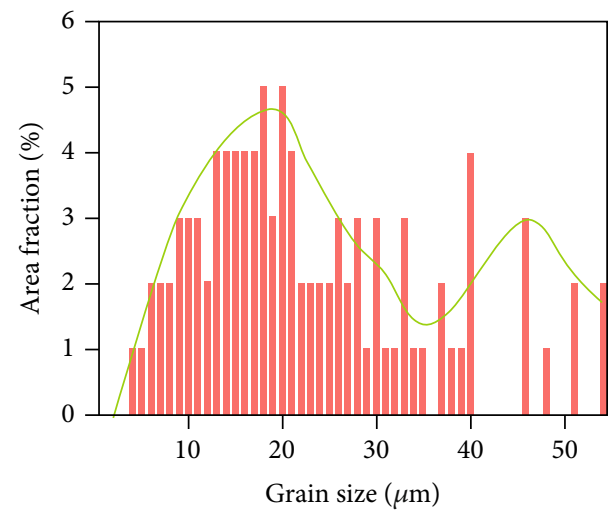

(d)

Figure 3: SEM micrographs (a, b), EBSD inverse pole figure mapping (c), and grain size statistics (d) of the MH alloy.

as artificial critical grain size of $35 \mu \mathrm{m}$ is chosen, as shown in Figures $3(\mathrm{c})$ and $3(\mathrm{~d})$. The volume fraction of the fine grains reaches $84.8 \%$.

The AC alloy has poor mechanical properties, as shown in Figure 4(a). The multiheterostructure brings a superior combination of high strength and good ductility to the AZ91 alloy. The tensile yield strength (TYS), ultimate tensile strength (UTS), and elongation (EL) of the $\mathrm{MH}$ alloy are improved by $240.5 \%, 175.0 \%$, and $80.3 \%$, respectively, compared to the AC alloy (Figure 4(a)). Moreover, the microhardness increment of the MH alloy is over 40\%, as shown in Figure 4(b).

3.2. Wear Behavior. Figure 5(a) shows the time evolution of the wear volume. The wear volume almost linearly increases with increasing duration time both for the AC alloy (from $0.234 \mathrm{~mm}^{3}$ to $1.915 \mathrm{~mm}^{3}$ ) and the $\mathrm{MH}$ alloy (from $0.247 \mathrm{~mm}^{3}$ to $2.622 \mathrm{~mm}^{3}$ ). The $\mathrm{MH}$ alloy exhibits a more rapidly increasing trend of the wear volume than the AC alloy, indicating a larger wear rate. Therefore, the $\mathrm{MH}$ alloy has a larger wear volume than the AC alloy under all duration time, although the difference is hard to be perceived under a short duration time. Figure 5(b) presents the wear volume as a function of the applied load. The wear volume of both alloys increases gradually with increasing the applied load and its growth trend of both alloys is similar. Apparently, the wear volume of the $\mathrm{MH}$ alloy (from $0.826 \mathrm{~mm}^{3}$ to $1.908 \mathrm{~mm}^{3}$ ) is larger than that of the AC alloy (from $0.701 \mathrm{~mm}^{3}$ to $1.690 \mathrm{~mm}^{3}$ ) at all the applied loads. The present 


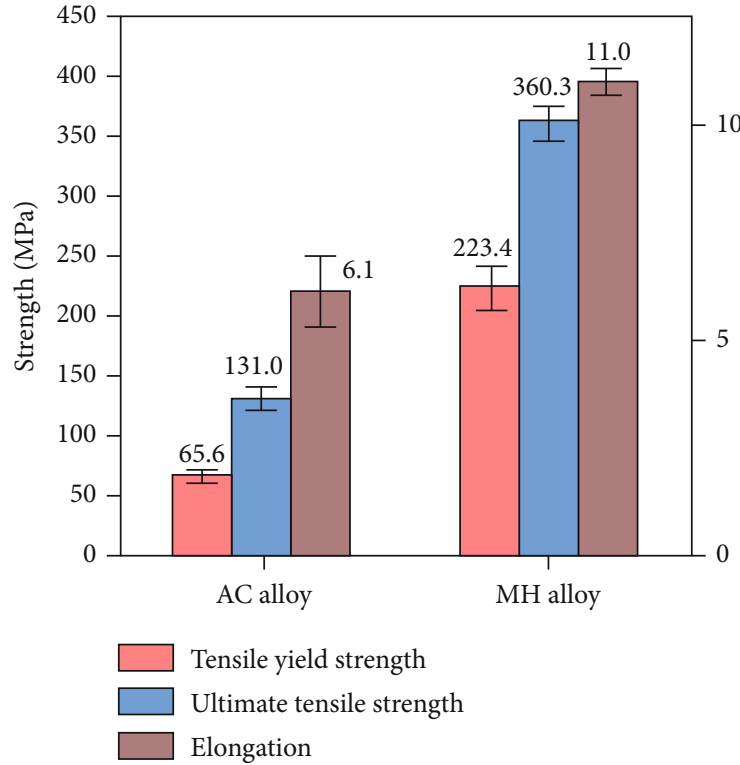

(a)

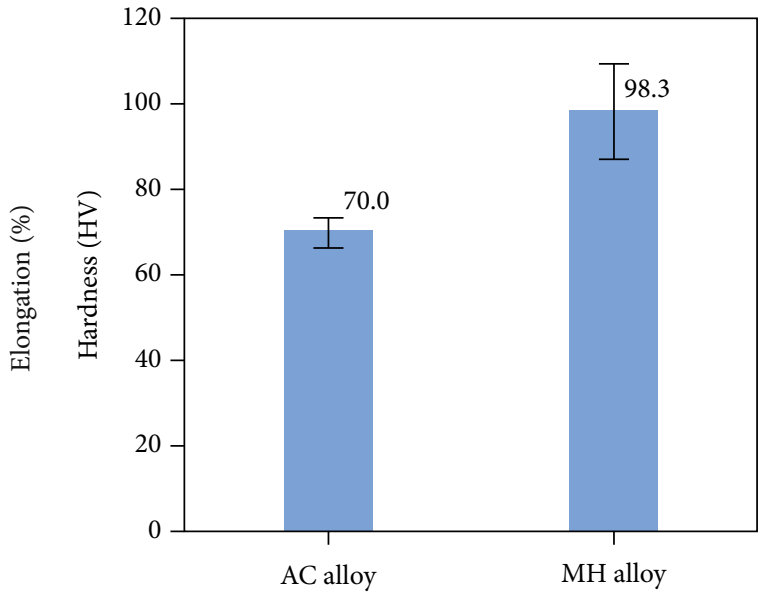

(b)

Figure 4: The mechanical properties $[7,30]$ (a) and microhardness (b) of the AC and MH alloys.

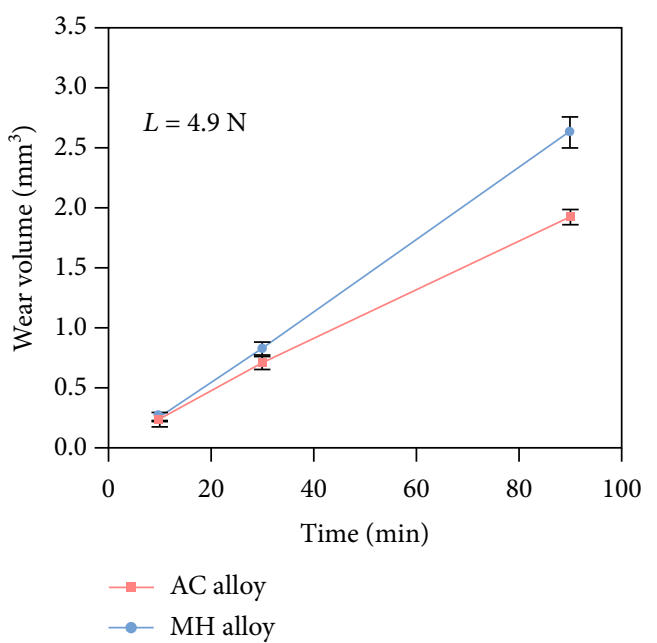

(a)

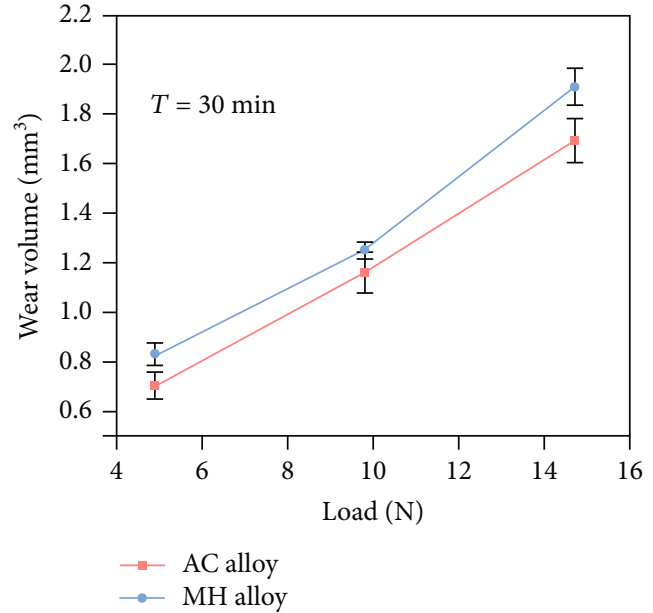

(b)

FIgUre 5: Wear volume of the AC and MH alloys as the function of the duration time $T$ (a) and the applied load $L$ (b).

results demonstrate that the $\mathrm{MH}$ alloy exhibits a poorer wear resistance than the AC alloy, although it has better mechanical properties.

Figure 6 shows the wear track cross-section profiles of the $\mathrm{AC}$ and $\mathrm{MH}$ alloys. Under short duration time or small applied load, the wear track of two alloys is similar, while it is slightly deeper for the MH alloy, as shown in Figures 6(a) and 6(c). Increasing duration time, both the wear track depth and width of the $\mathrm{MH}$ alloy are growing faster than that of the AC alloy, as shown in Figure 6(b), indicating rapidly increased wear volume. Increasing the applied load, the discrepancy of the wear track depth between the AC alloy and the $\mathrm{MH}$ alloy dramatically grows, but the wear track widths of two alloys are similar.
Figure 7 shows the evolution of the $\mathrm{COF}$ for the $\mathrm{AC}$ and $\mathrm{MH}$ alloys under the applied load of $4.9 \mathrm{~N}$ and $14.7 \mathrm{~N}$. After a rapid increase, the COF tends to be steady for all the samples, although the fluctuation is still visible. It is evident that the $\mathrm{AC}$ alloy shows more drastic $\mathrm{COF}$ fluctuation than the $\mathrm{MH}$ alloy. Furthermore, the COF fluctuation is influenced by the applied load, as shown in Figure 7. To be specific, the lower applied load, the more fluctuant COF.

The average $\mathrm{COF}$ of the $\mathrm{AC}$ and $\mathrm{MH}$ alloys during the steady wear stage was calculated, and the result is shown in Figure 8. As the duration time increases, the COF of these two alloys increases first and then decreases. The COF of the AC alloy is higher than that of the $\mathrm{MH}$ alloy under different duration times (Figure 8(a)). The highest COF is 0.341 for 

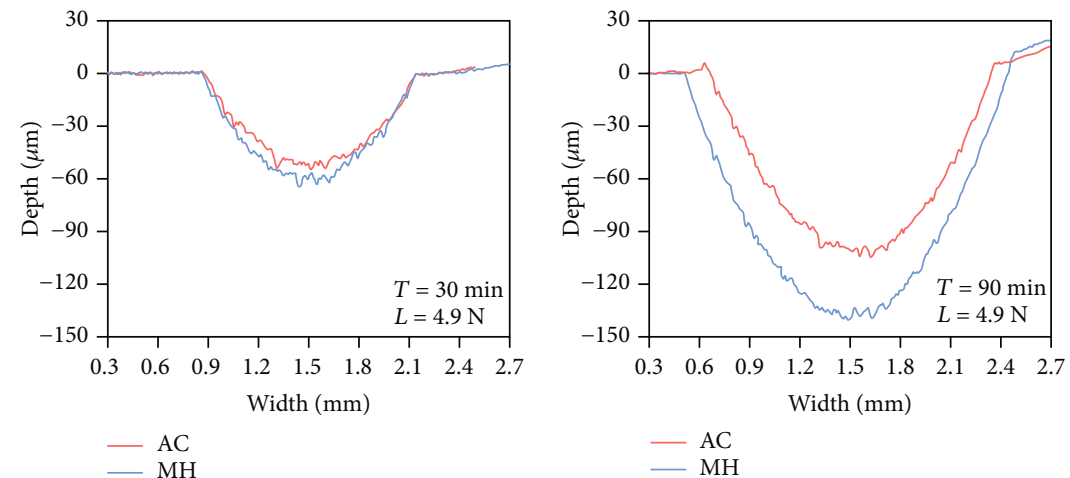

(a)

(b)

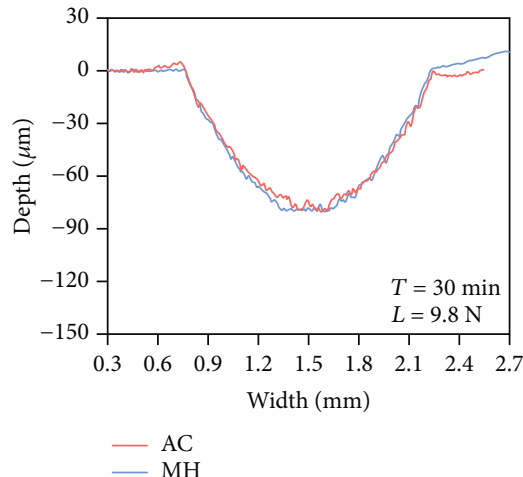

(c)

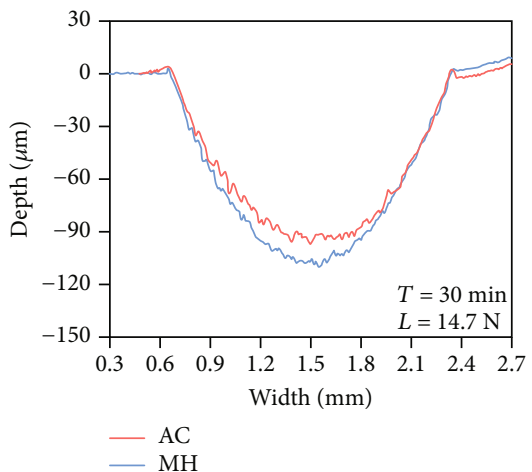

(d)

FIgURE 6: The wear track cross-section profiles of the AC and MH alloys under the applied load $L$ of $4.9 \mathrm{~N}(\mathrm{a}, \mathrm{b})$ and the duration time $T$ of $30 \min (c, d)$.

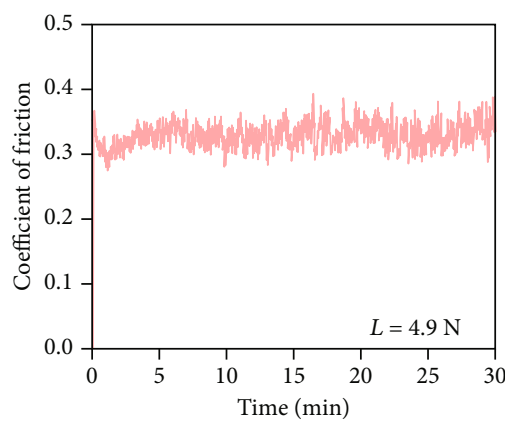

- AC alloy

(a)

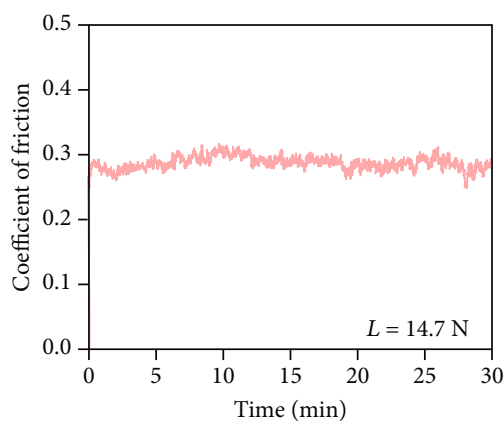

— AC alloy

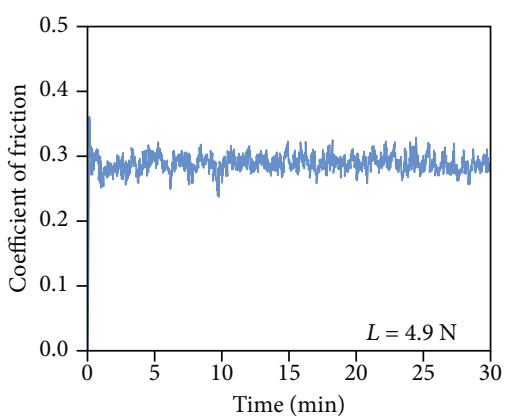

— MH alloy

(b)

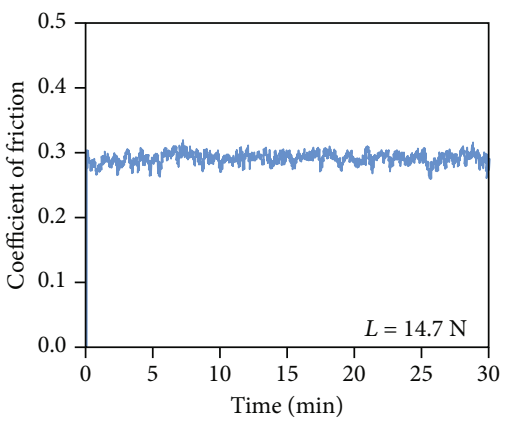

— MH alloy

(c)

(d)

Figure 7: The fluctuation of the COF values of the AC (a, c) and MH (b, d) alloys under the applied load $L$ of $4.9 \mathrm{~N}(\mathrm{a}, \mathrm{b})$ and $14.7 \mathrm{~N}(\mathrm{c}, \mathrm{d})$. 


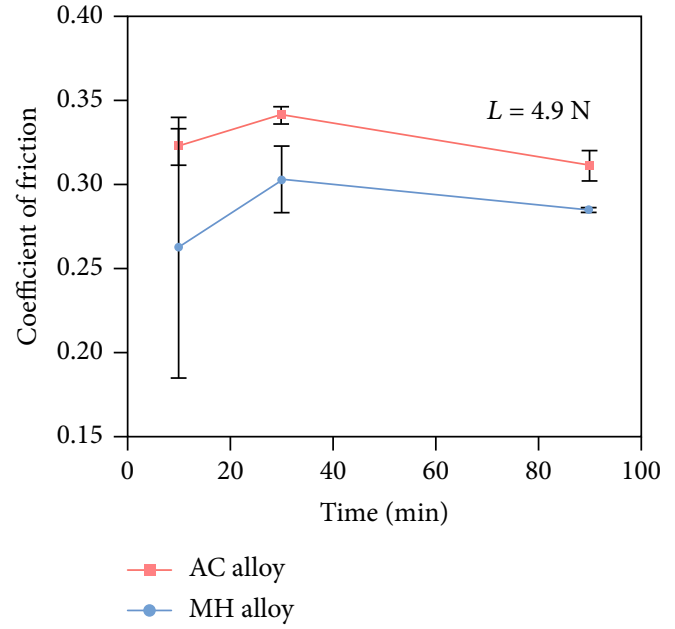

(a)

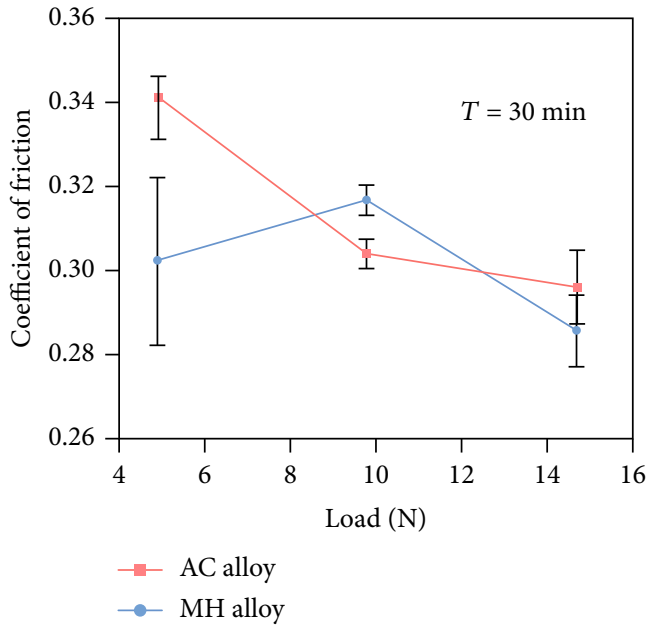

(b)

Figure 8: The average COF of the AC and MH alloys versus the different duration times $T$ (a) and applied loads $L$ (b).

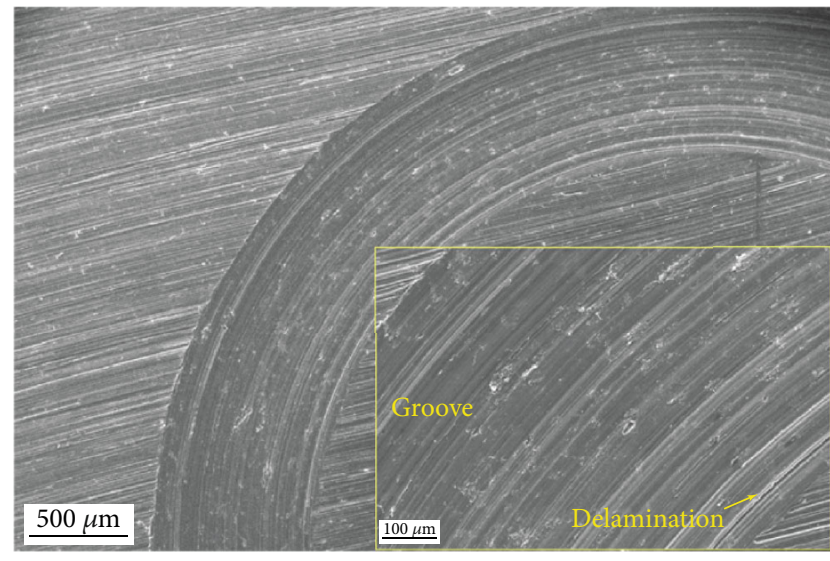

(a)

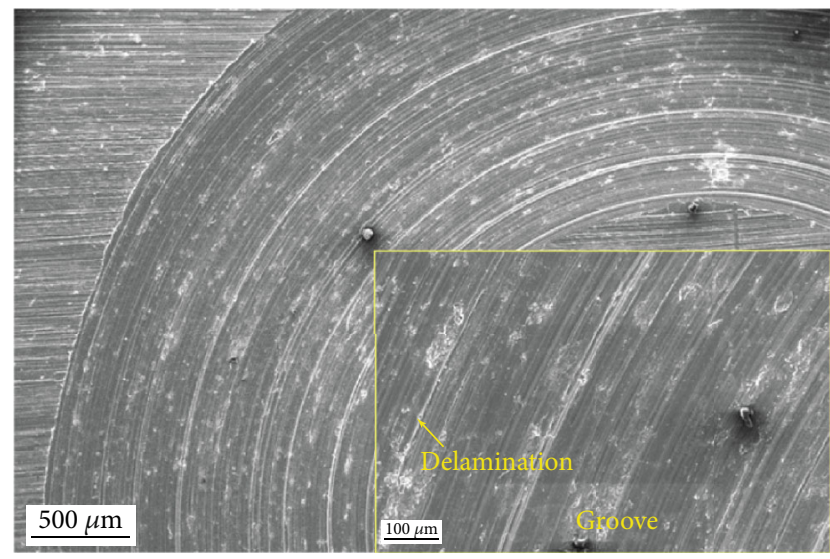

(c)

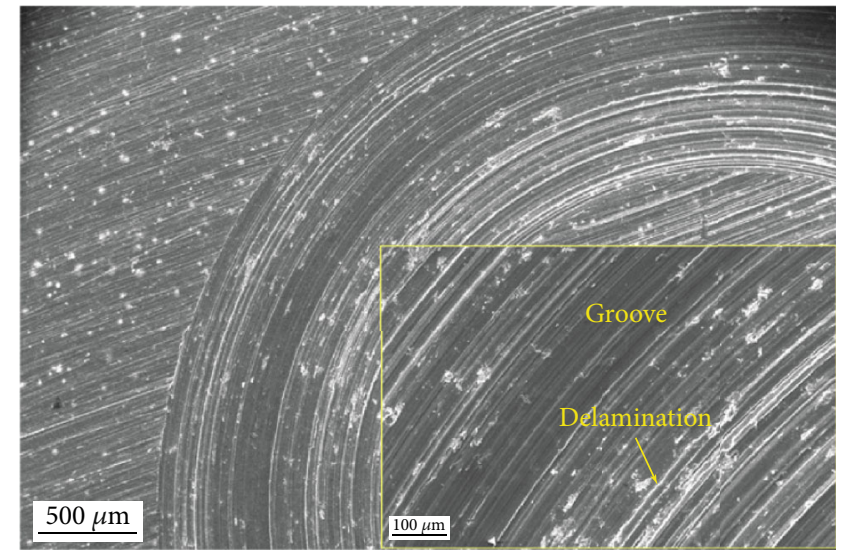

(b)

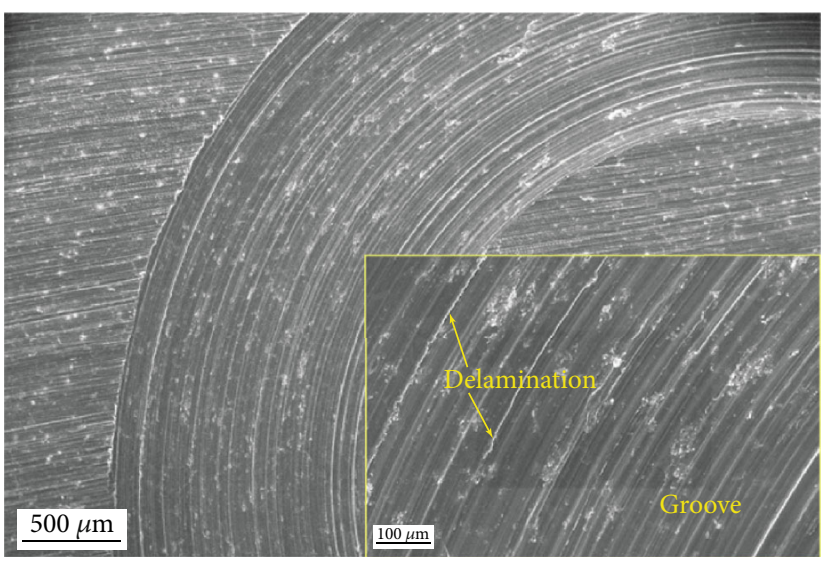

(d)

Figure 9: The SEM images of the typical wear surfaces of the AC alloy: (a) $T=10 \mathrm{~min}, L=4.9 \mathrm{~N}$; (b) $T=30 \mathrm{~min}, L=4.9 \mathrm{~N}$; (c) $T=90 \mathrm{~min}$, $L=4.9 \mathrm{~N}$; (d) $T=30 \mathrm{~min}, L=9.8 \mathrm{~N}$.

the AC alloy, while it is decreased to 0.302 for the $\mathrm{MH}$ alloy. Nevertheless, under different applied loads, the variation trend of COF of the AC and $\mathrm{MH}$ alloys is quite different, as shown in Figure 8(b). The COF of the AC alloy (from 0.341 to 0.296$)$ rapidly decreases, followed by a relatively gentle descent. In contrast, the $\mathrm{COF}$ of the $\mathrm{MH}$ alloy first increases and then decreases with increasing the applied load. Therefore, the MH alloy exhibits a low COF at an applied load of 


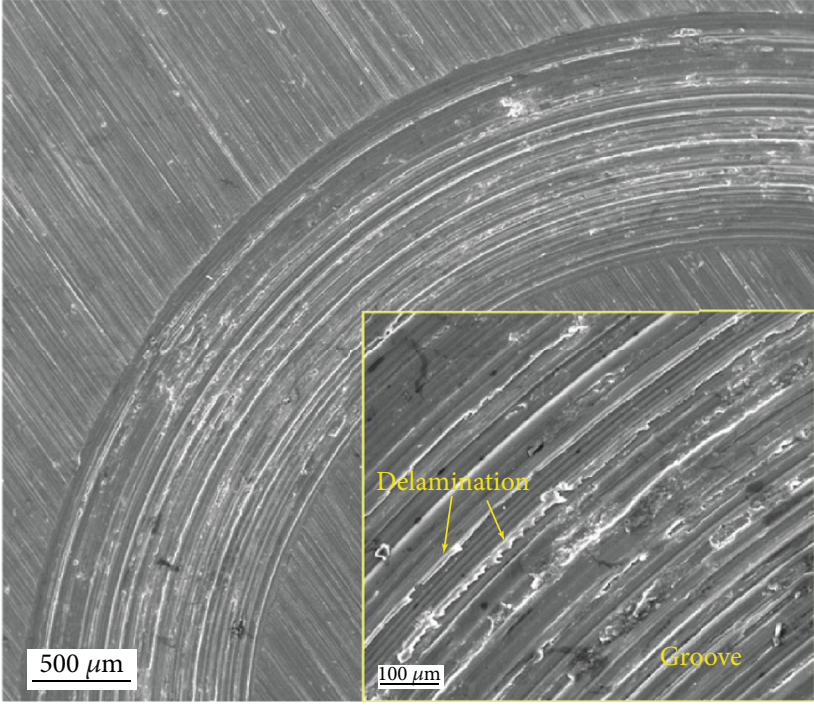

(a)

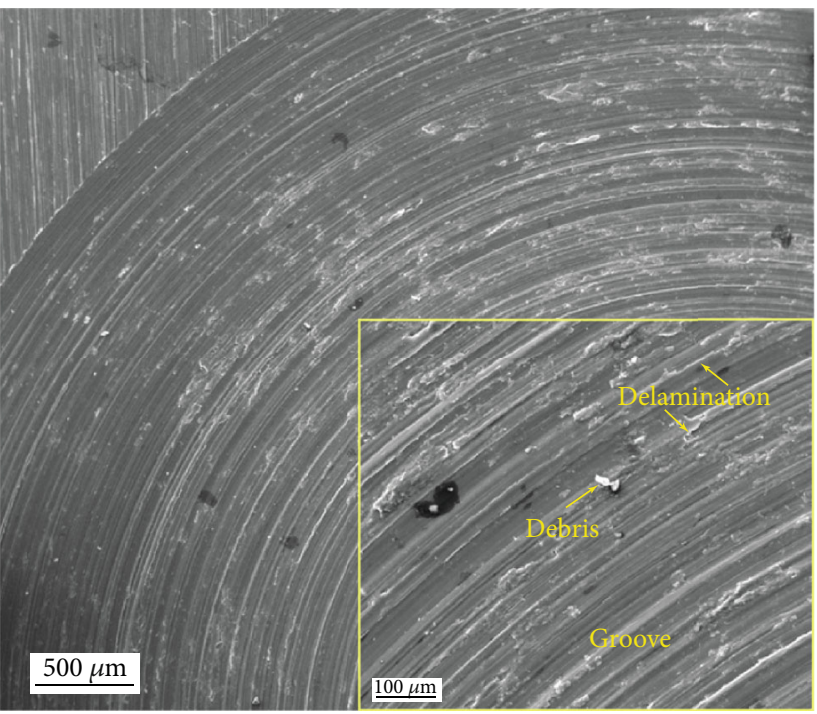

(c)

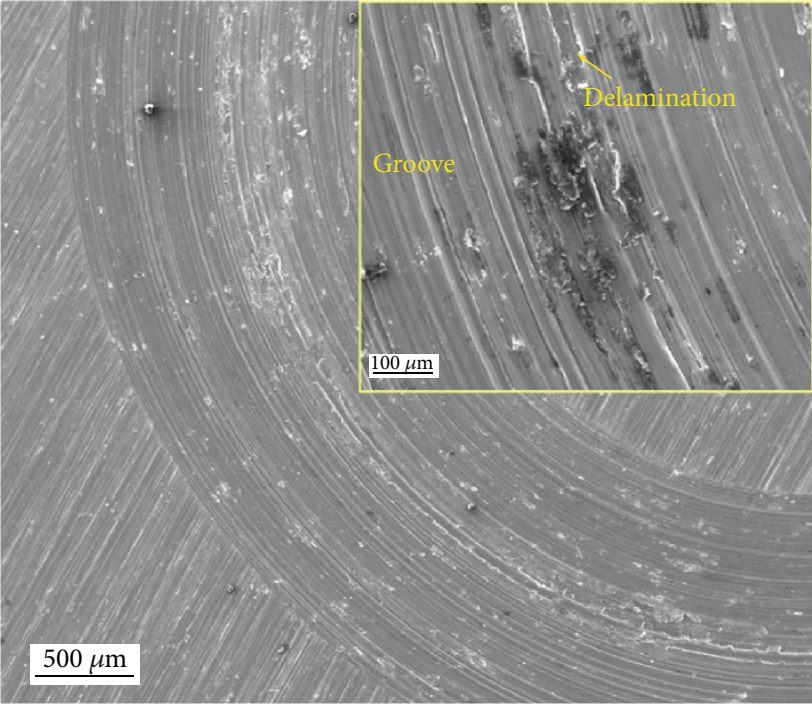

(b)

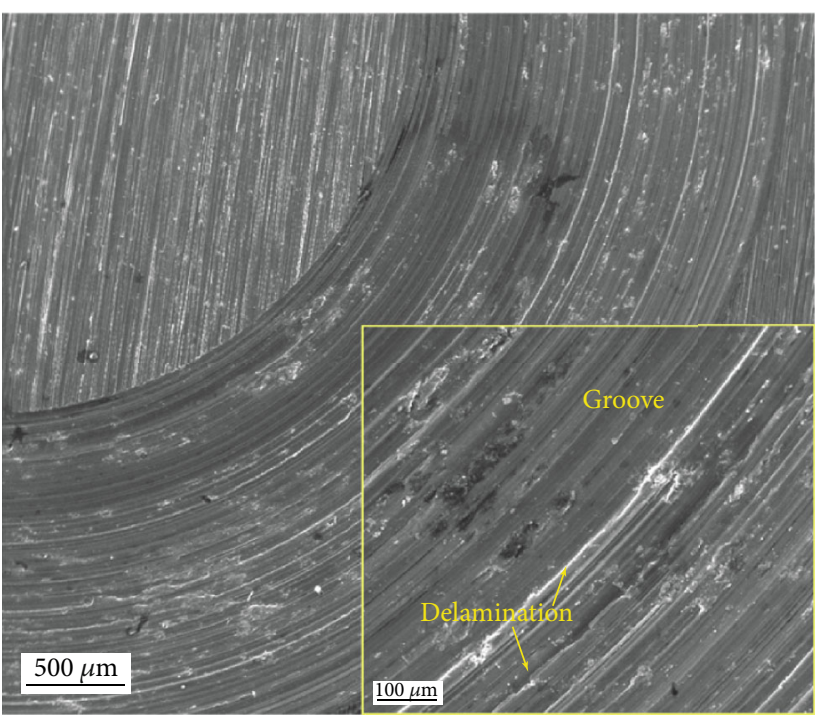

(d)

Figure 10: The SEM images of the typical wear surfaces of the MH alloy: (a) $T=10 \min , L=4.9 \mathrm{~N}$; (b) $T=30 \mathrm{~min}, L=4.9 \mathrm{~N}$; (c) $T=90 \mathrm{~min}$ , $L=4.9 \mathrm{~N}$; (d) $T=30 \mathrm{~min}, L=9.8 \mathrm{~N}$.

$4.9 \mathrm{~N}(0.262)$ and $14.7 \mathrm{~N}(0.286)$. As a whole, the MH alloy shows the relatively lower COF compared to the AC alloy under different duration times and applied loads.

3.3. Wear Mechanism. The morphologies of the wear surface were further characterized using SEM combined with EDS to reveal wear mechanism. Figures 9 and 10 present the SEM images of the typical wear surfaces of the AC and $\mathrm{MH}$ alloys. Along the sliding direction, numerous grooves, ridges, and debris can be observed on the wear surface of both alloys at all conditions, representing the typical morphologies of abrasive wear. Therefore, the abrasive wear is the primary wear mechanism for both alloys. Besides, some adhesion marks and delamination are visible for both alloys, indicating the occurrence of adhesion wear and delamination wear. Some black stains can be found in both alloys. The EDS analysis demonstrates that these stains contain high-concentration $\mathrm{O}$ element, giving rise to the occurrence of oxidation wear, as shown in Figure 11. In comparison, the $\mathrm{MH}$ alloy shows relatively severer adhesion, delamination, and oxidation. As the duration time and applied load increase, the wear track width of both alloys increase, but it is hard to tell the difference in the wear mechanism. The present result is consistent with these previous researches that the dominant wear mechanism of the AZ91 alloy at low load and sliding is abrasive wear [33, 34], and confirms that the $\mathrm{MH}$ alloy has almost same wear mechanism to the AC alloy.

The $\mathrm{MH}$ alloy exhibits finer grains compared to the $\mathrm{AC}$ alloy. The fine grains benefit to the improvement in strength and ductility due to the well-known Hall-Petch law. In contrast, fine grain is a sword with double blades for the wear 

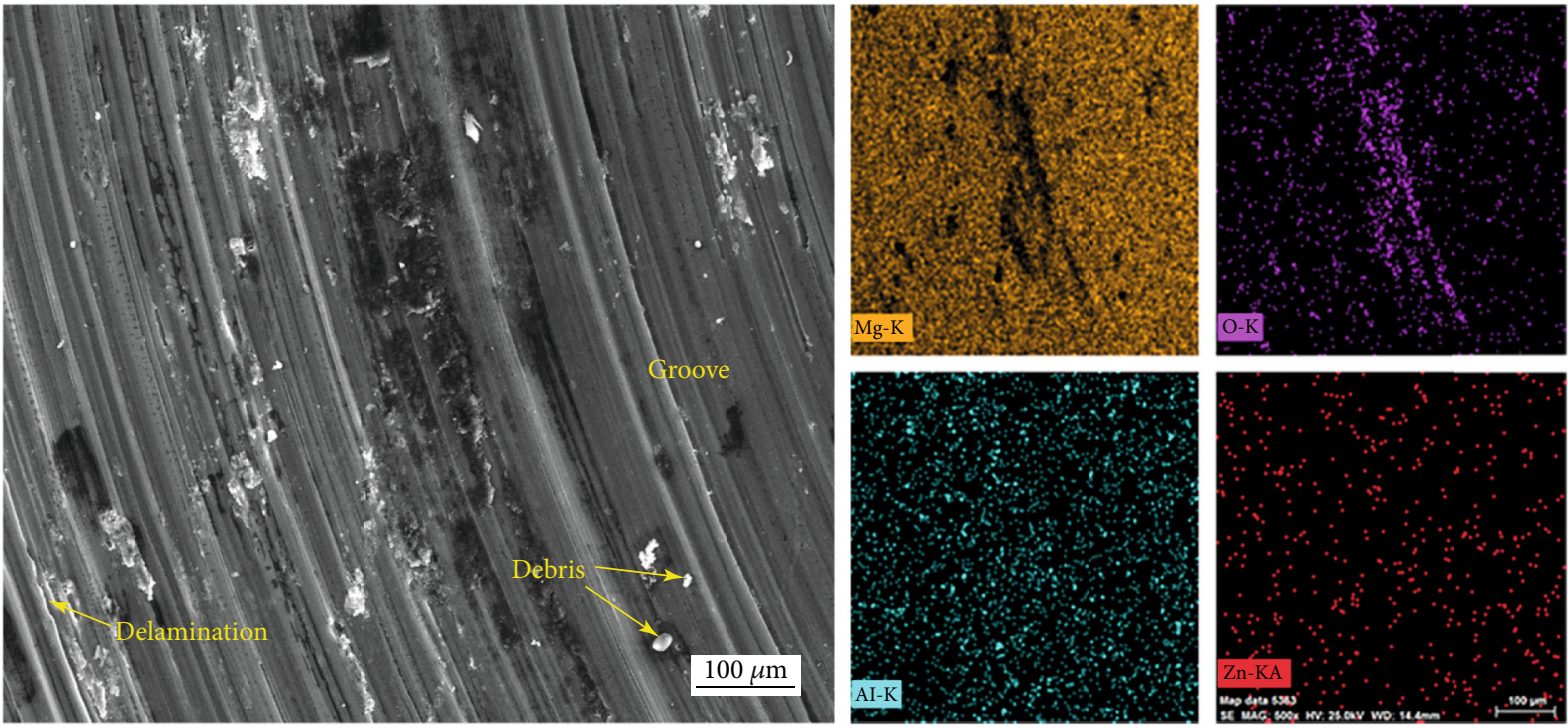

FIgURE 11: Large-magnification SEM images and EDS elemental mappings of the typical worn surfaces of the MH alloy under the applied load $L$ of $4.9 \mathrm{~N}$ and the duration time $T$ of $30 \mathrm{~min}$.

behavior, which not only can hinder wear due to the improved hardness but also can accelerate wear due to the abundant unstable grain boundaries. During the dry sliding wear process, the high friction heat will deteriorate the instability of the grain boundaries, which is confirmed by the observed relatively severe oxidation. Also, the modification of the precipitate microstructure impacts the wear behavior. The fine lamellar $\gamma$-phase precipitates in the $\mathrm{MH}$ alloy may be obstructive to improve wear resistance, because the small precipitates are easy to be dug out when the abrasive wear prevails. Therefore, the MH alloy exhibits larger wear volume than the AC alloy during the present dry sliding wear condition, although it has significantly improved strength, ductility, and hardness. Indeed, the decreased and improved wear resistance are both frequently reported for the ECAP metals in literature. For example, Patil et al. [35] indicated that the ECAP processed samples displayed a poorer wear resistance as compared to the as-cast sample at $20 \mathrm{~N}$ and $30 \mathrm{~N}$ loads, but a decreased wear resistance at $10 \mathrm{~N}$. On contrast, $\mathrm{Xu}$ et al. [36] reported that the wear volume of ECAPprocessed AZ31 is smaller than for the as-received unprocessed alloy. Therefore, the wear resistance of the $\mathrm{MH}$ alloy prepared by ECAP is not only related to its physical properties but also significantly related to the wear condition. One should reasonably use the $\mathrm{MH}$ alloy considering the service conditions to seek advantages and avoid disadvantages.

\section{Conclusion}

In this work, the dry sliding wear behavior of the MH AZ91 alloy with multiheterostructure was investigated, which was prepared via the combined processing route of industrialscale ECAP and aging. Although the MH AZ91 alloy exhibits high-desirable strength-ductility synergy due to its special multiheterostructure, it shows a poorer wear resistance compared to the AC alloy at the present condition. As a whole, the $\mathrm{MH}$ alloy shows the relatively lower $\mathrm{COF}$ compared to the AC alloy. The difference in wear volume between two alloys is hard to be perceived under a short duration time, while the $\mathrm{MH}$ alloy has a much larger wear volume than the AC alloy under a long duration time. The wear volume of both alloys is almost linearly increased with the increase in the applied load. The wear mechanism of both alloys mainly involves abrasive wear, as well as mild adhesion, delamination, and oxidation. In comparison, the $\mathrm{MH}$ alloy shows relatively severer adhesion, delamination, and oxidation. The poor wear resistance of the MH alloy at the present dry sliding wear condition is linked to the abundant grain boundaries and small and fine precipitates.

\section{Data Availability}

The data used to support the findings of this study are available from the corresponding author upon request.

\section{Conflicts of Interest}

The authors declare that they have no competing interests.

\section{Acknowledgments}

The work was supported by the Fundamental Research Funds for the Central Universities (grant no. B200202121) and the National Natural Science Foundation of China (grant no. 51774109 and 51979099).

\section{References}

[1] J. Song, J. She, D. Chen, and F. Pan, "Latest Research Advances on Magnesium and Magnesium Alloys Worldwide," Journal of Magnesium and Alloys, vol. 8, no. 1, pp. 1-41, 2020. 
[2] H. Wu, Z. Shi, X. Zhang et al., "Achieving an acid resistant surface on magnesium alloy via bio-inspired design," Applied Surface Science, vol. 478, pp. 150-161, 2019.

[3] G. Wu, Y. Zhao, X. Zhang, J. M. Ibrahim, and P. K. Chu, "Selfprotection against corrosion of aged magnesium alloy in simulated physiological environment," Corrosion Science, vol. 68, pp. 279-285, 2013.

[4] C. Liu, Z. Ren, Y. Xu, S. Pang, X. Zhao, and Y. Zhao, "Biodegradable magnesium alloys developed as bone repair materials: a review," Scanning, vol. 2018, Article ID 9216314, 15 pages, 2018.

[5] G. Wu, H. Wu, X. Zhang, S. Xiao, Z. Wu, and P. K. Chu, "Electrochemical degradation and extraction capability of magnesium wastes in sewage treatment," Materials and Design, vol. 111, pp. 537-540, 2016.

[6] G. Wu, K. Chan, L. Zhu, L. Sun, and J. Lu, "Dual-phase nanostructuring as a route to high-strength magnesium alloys," Nature, vol. 545, no. 7652, pp. 80-83, 2017.

[7] J. Sun, B. Xu, Z. Yang et al., "Achieving excellent ductility in high-strength Mg-10.6Gd-2 Ag alloy via equal channel angular pressing," Journal of Alloys and Compounds, vol. 817, 2020.

[8] X. Ma, Q. Jiao, L. J. Kecskes, J. A. el-Awady, and T. P. Weihs, "Effect of basal precipitates on extension twinning and pyramidal slip: a micro-mechanical and electron microscopy study of a Mg-Al binary alloy," Acta Materialia, vol. 189, pp. 35-46, 2020.

[9] J. Zheng and B. Chen, "Atomic-scale characterization of the equilibrium $\beta$ phase in $\mathrm{Mg}-\mathrm{Nd}-\mathrm{Y}$ alloy by means of HAADFSTEM," Scanning, vol. 38, no. 6, pp. 743-746, 2016.

[10] S. Tang, T. Xin, W. Xu et al., "Precipitation strengthening in an ultralight magnesium alloy," Nature Communications, vol. 10, no. 1, p. 1003, 2019.

[11] J. Zhang, S. Liu, R. Wu, L. Hou, and M. Zhang, "Recent developments in high-strength Mg-RE-based alloys: focusing on Mg-Gd and Mg-Y systems," Journal of Magnesium and Alloys, vol. 6, no. 3, pp. 277-291, 2018.

[12] S. You, Y. Huang, K. U. Kainer, and N. Hort, "Recent research and developments on wrought magnesium alloys," Journal of Magnesium and Alloys, vol. 5, no. 3, pp. 239-253, 2017.

[13] F. Zhao, T. Suo, B. Chen, and Y. L. Li, "Strength-ductility combination of fine-grained magnesium alloy with high deformation twin density," Journal of Alloys and Compounds, vol. 798, pp. 350-359, 2019.

[14] B. Xu, J. Sun, Z. Yang et al., "Microstructure and anisotropic mechanical behavior of the high-strength and ductility AZ91 $\mathrm{Mg}$ alloy processed by hot extrusion and multi-pass RDECAP," Materials Science and Engineering A, vol. 780, p. 139191, 2020.

[15] S.-J. Meng, H. Yu, S.-D. Fan et al., "Recent Progress and development in extrusion of rare earth free Mg alloys: a review," Acta Metallurgica Sinica (English Letters), vol. 32, no. 2, pp. 145-168, 2019.

[16] H. Yu, Y. Xin, M. Wang, and Q. Liu, "Hall-Petch relationship in Mg alloys: a review," Journal of Materials Science and Technology, vol. 34, no. 2, pp. 248-256, 2018.

[17] L. R. Xiao, X. F. Chen, Y. Cao et al., "Solute segregation assisted nanocrystallization of a cold-rolled $\mathrm{Mg}-\mathrm{Ag}$ alloy during annealing," Scripta Materialia, vol. 177, pp. 69-73, 2020.

[18] Y. Fu, J. Sun, Z. Yang et al., "Aging behavior of a fine-grained Mg-10.6Gd-2Ag alloy processed by ECAP," Materials Characterization, vol. 165, p. 110398, 2020.
[19] W. Wang, P. Han, P. Peng et al., "Friction stir processing of magnesium alloys: a review," Acta Metallurgica Sinica (English Letters), vol. 33, no. 1, pp. 43-57, 2020.

[20] $\mathrm{Y} . \mathrm{Hu}$ and $\mathrm{X}$. $\mathrm{Wu}$, "Perspective on hetero-deformation induced (HDI) hardening and back stress," Materials Research Letters, vol. 7, no. 10, pp. 393-398, 2019.

[21] I. A. Ovid'Ko, R. Z. Valiev, and Y. T. Zhu, "Review on superior strength and enhanced ductility of metallic nanomaterials," Progress in Materials Science, vol. 94, pp. 462-540, 2018.

[22] Y.-F. Jia, Y.-X. Liu, J. Huang et al., "Fatigue-induced evolution of nanograins and residual stress in the nanostructured surface layer of Ti-6Al-4V," Materials Science and Engineering A, vol. 764, 2019.

[23] Y.-F. Jia, R.-J. Pan, P.-Y. Zhang et al., "Enhanced surface strengthening of titanium treated by combined surface deeprolling and oxygen boost diffusion technique," Corrosion Science, vol. 157, pp. 256-267, 2019.

[24] B. Wang, D. Xu, L. Sheng, E. Han, and J. Sun, "Deformation and fracture mechanisms of an annealing-tailored "bimodal" grain-structured Mg alloy," Journal of Materials Science and Technology, vol. 35, no. 11, pp. 2423-2429, 2019.

[25] M. Zha, H. M. Zhang, Z. Y. Yu et al., "Bimodal microstructure - a feasible strategy for high-strength and ductile metallic materials," Journal of Materials Science and Technology, vol. 34, no. 2, pp. 257-264, 2018.

[26] S. M. Ramezani, A. Zarei-Hanzaki, H. R. Abedi, A. SalandariRabori, and P. Minarik, "Achievement of fine-grained bimodal microstructures and superior mechanical properties in a multi-axially forged GWZ magnesium alloy containing LPSO structures," Journal of Alloys and Compounds, vol. 793, pp. 134-145, 2019.

[27] S. Liu, J. Zhang, X. Chen et al., "Improving mechanical properties of heterogeneous mg-Gd alloy laminate via accumulated extrusion bonding," Materials Science and Engineering A, vol. 785, p. 139324, 2020.

[28] W. Rong, Y. Zhang, Y. Wu et al., "The role of bimodal-grained structure in strengthening tensile strength and decreasing yield asymmetry of Mg-Gd-Zn-Zr alloys," Materials Science and Engineering A, vol. 740-741, pp. 262-273, 2019.

[29] C. Xu, G. H. Fan, T. Nakata et al., "Deformation behavior of ultra-strong and ductile Mg-Gd-Y-Zn-Zr alloy with bimodal microstructure," Metallurgical and Materials Transactions A: Physical Metallurgy and Materials Science, vol. 49, no. 5, pp. 1931-1947, 2018.

[30] J. Sun, B. Xu, Z. Yang et al., "Developing an industrial-scale ECAP Mg-Al-Zn alloy with multi-heterostructure for synchronously high strength and good ductility," Materials Characterization, vol. 164, p. 110341, 2020.

[31] J. Sun, Z. Yang, H. Liu et al., "Tension-compression asymmetry of the AZ91 magnesium alloy with multi-heterogenous microstructure," Materials Science and Engineering A, vol. 759, pp. 703-707, 2019.

[32] J. Sun, Z. Yang, J. Han et al., "High strength and ductility AZ91 magnesium alloy with multi-heterogenous microstructures prepared by high-temperature ECAP and short-time aging," Materials Science and Engineering A, vol. 734, pp. 485-490, 2018.

[33] B. N. Sahoo and S. K. Panigrahi, "Development of wear maps of in-situ TiC+TiB2 reinforced AZ91 Mg matrix composite with varying microstructural conditions," Tribology International, vol. 135, pp. 463-477, 2019. 
[34] S. García-Rodríguez, B. Torres, A. Maroto, A. J. López, E. Otero, and J. Rams, "Dry sliding wear behavior of globular AZ91 magnesium alloy and AZ91/SiCp composites," Wear, vol. 390-391, pp. 1-10, 2017.

[35] A. Patil, S. Bontha, and M. R. Ramesh, "Effect of ECAP on sliding wear behaviour of Mg-Zn-Gd-Zr alloy," Materials Today: Proceedings, vol. 20, pp. 97-102, 2020.

[36] J. Xu, X. Wang, X. Zhu et al., "Dry sliding wear of an AZ31 magnesium alloy processed by equal-channel angular pressing," Journal of Materials Science, vol. 48, no. 11, pp. 41174127, 2013. 